\title{
Histidine Decarboxylase Expression as a New Sensitive and Specific Marker for Small Cell Lung Carcinoma
}

\author{
Yasumasa Matsuki, M.D., Akihide Tanimoto, M.D., Ph.D., Tetsuo Hamada, M.D., Ph.D., \\ Yasuyuki Sasaguri, M.D., Ph.D. \\ Department of Pathology and Cell Biology (YM, TH, YS), School of Medicine, University of Occupational \\ and Environmental Health, Kitakyushu; and Department of Pathology (AT), Toranomon Hospital, \\ Minato-ku, Japan
}

Histidine decarboxylase is one of the enzymes of the amine precursor uptake and decarboxylation system and is known to be distributed in mast cells and enterochromaffin-like cells. With the hypothesis that histidine decarboxylase expression is a marker for neuroendocrine differentiation, we studied the immunoreactivity of histidine decarboxylase in neuroendocrine cells and tumors of the thyroid gland, adrenal medulla, lung, and gastrointestinal tract. Formalin-fixed paraffin sections were subjected to immunohistochemistry using antihistidine decarboxylase antibody, and the sensitivity and specificity were compared with those of conventional neuroendocrine markers (CD56, chromogranin A, synaptophysin, and neuron-specific enolase). Enterochromaffin or enterochromaffinlike cells, adrenal chromaffin cells, and thyroid C-cells were positive for histidine decarboxylase, and related tumors (carcinoid tumor, pheochromocytoma, medullary carcinoma) showed a high percentage of positive staining. Furthermore, we used the antibody to distinguish small cell lung carcinoma from non-neuroendocrine lung carcinoma and also to detect neuroendocrine differentiation in large-cell neuroendocrine carcinoma and gastrointestinal small-cell carcinoma. The anti-histidine decarboxylase antibody stained most small cell lung carcinoma ( 18 of 23 , sensitivity 0.78 ), and was rarely reactive with non-neuroendocrine lung tumors (2 of 44; specificity, 0.95$)$. These values were close to those obtained from CD56 staining (sensitivity/ specificity, 0.87/0.98). Histidine decarboxylase was also positive for 6 of 12 large cell neuroendocrine

Copyright (C) 2003 by The United States and Canadian Academy of Pathology, Inc.

VOL. 16, NO. 1, P. 72, 2003 Printed in the U.S.A.

Date of acceptance: October 3, 2002.

Address reprint requests to: Yasuyuki Sasaguri, M.D., Ph.D., Department of Pathology and Cell Biology, University of Occupational and Environmental Health, 1-1 Iseigaoka, Yahatanishi, Kitakyushu 807-8555, Japan; e-mail: yasu-s@med.uoeh-u.ac.jp; fax: 8193-603-8518.

DOI: $10.1097 / 01 . M P .0000044485 .14910 .3 A$ carcinomas and 4 of 7 gastrointestinal small cell carcinomas. In conclusion, we demonstrated that histidine decarboxylase is useful to distinguish between small cell lung carcinoma and nonneuroendocrine carcinoma and to demonstrate neuroendocrine differentiation.

KEY WORDS: Histidine decarboxylase, Immunohistochemistry, Neuroendocrine carcinoma, Small cell lung carcinoma.

Mod Pathol 2003;16(1):72-78

Although numerous immunohistochemical markers for neuroendocrine differentiation have been proposed, their rather low sensitivity and heterogeneous staining often limit their usefulness as diagnostic tools. For example, chromogranin A is a matrix protein associated with neurosecretory granules and therefore is absolutely specific for neuroendocrine differentiation $(1,2)$. However, because detectability is directly related to the number of neurosecretory granules, infrequent staining or absence of staining for chromogranin A has been reported in cases of small cell lung carcinoma (3-5). On the other hand, anti-neuron-specific enolase (NSE) antibody is highly reactive for neuroendocrine tumors, but its specificity is poor because of cross-reactivity (6). Recent studies have revealed that new makers such as CD56 and microtubulesassociated protein-2 provide a higher sensitivity for small cell lung carcinoma with a relatively lower frequency of heterogeneous staining $(7,8)$.

L-histidine decarboxylase (HDC) is the ratelimiting enzyme for production of histamine by decarboxylation of L-histidine and is distributed in various types of cells, including mast cells, basophiles, enterochromaffin-like cells, and monocytes/ macrophages (9-12). Histamine plays a major role in allergy, inflammation, and cardiovascular hemodynamics (13-15), and histamine and other factors released from carcinoid tumor are related to the clinical condition known as carcinoid syndrome 
$(16,17)$. Recent studies have also suggested a potential role of histamine in the proliferation of some types of human tumor cells via auto/paracrine activity (18-20). HDC, like L-dopa decarboxylase, is one of the enzymes involved in amine precursor uptake and decarboxylation, which is considered to be a common biochemical feature of the so-called amine precursor uptake and decarboxylation system $(21,22)$. In fact, a high level of dopa decarboxylase activity has been reported in small cell lung carcinoma (23), and $>80 \%$ of endocrine or neuroendocrine tumors have been found to express dopa decarboxylase (24). These findings suggest the possibility that HDC may be another marker for neuroendocrine differentiation. One recent study has revealed the expression of HDC in biopsied materials of small cell lung carcinoma (25). To our knowledge, however, no systematic immunohistochemical study of HDC expression in neuroendocrine or endocrine tumors has been reported.

We planned this study to screen the expression of HDC in lung and gastrointestinal neuroendocrine tumors. Furthermore, we compared the sensitivity and specificity of HDC staining with those of widely used neuroendocrine markers, including NSE, chromogranin A, synaptophysin, and CD56.

\section{MATERIALS AND METHODS}

\section{Classification of Tumors}

One hundred and eleven surgically resected lung tumors were examined in the Department of $\mathrm{Pa}$ thology and Cell Biology at University of Occupational and Environmental Health in Kitakyushu, Japan. These cases were classified according to the World Health Organization histological typing of lung tumors (3rd edition; 26) and included carcinoid tumors, small cell lung carcinomas, large cell neuroendocrine carcinomas, classic large cell carcinomas, adenocarcinomas, and squamous cell car- cinomas (Table 1). Large cell neuroendocrine carcinomas were classified according to the criteria described by Travis et al. (27). The diagnosis of small cell lung carcinoma and other carcinoma is based primarily on light-microscopic observation. Twenty-three cases of carcinoid tumors and adenocarcinoma/squamous cell carcinomas with small cell carcinoma or neuroendocrine carcinoma components of the gastrointestinal tract were also examined. As a positive control, 15 cases of adrenal pheochromocytomas and 4 cases of medullary carcinomas of the thyroid gland were also selected. The diagnosis of all these cases was confirmed by at least three board-certified surgical pathologists.

\section{Immunohistochemistry}

Immunostaining was performed with the EnVision method (DAKO). Deparaffinized and rehydrated 5- $\mu \mathrm{m}$ sections were incubated with $3 \% \mathrm{H}_{2} \mathrm{O}_{2}$ for 10 minutes to block endogenous peroxidase activity. Sections were then rinsed and incubated with primary antibodies against chromogranin A (CGA; DAKO M869), synaptophysin (SYN; DAKO M776), NSE (DAKO M873), CD56 (Nichirei clone 1B6, Tokyo, Japan), and L-histidine decarboxylase (HDC; Progen, Heidelberg, Germany) according to the manufacturer's instructions. The rabbit polyclonal anti-HDC antibody raised against rat recombinant HDC is cross-reactive with human HDC (12). The second peroxidase-labeled antibody was applied and incubated with a solution of $20 \mathrm{mg}$ of 3,3'diaminobenzidene tetrahydrochloride, $65 \mathrm{mg}$ of sodium azide, and $20 \mu \mathrm{L}$ of $\mathrm{H}_{2} \mathrm{O}_{2}$ in $100 \mathrm{~mL}$ of Tris$\mathrm{HCl}(50 \mathrm{~mm}, \mathrm{pH}$ 7.6). After counterstaining with Meyer's hematoxylin, the sections were observed by light microscopy. For these markers, staining was considered to be positive if $\geq 5 \%$ of tumor cells were reactive, and was classified into two groups: (1) focally positive staining in $<10 \%$ of tumor cells,

TABLE 1. Immunohistochemical Results of Neuroendocrine (NE) Marker

\begin{tabular}{|c|c|c|c|c|c|}
\hline Type & CD56 & CGA & SYN & NSE & HDC \\
\hline Pheochromocytoma & ND & $15 / 15(100)$ & ND & ND & $15 / 15(100)$ \\
\hline Medullary carcinoma & ND & 4/4 (100) & ND & ND & 4/4 (100) \\
\hline \multicolumn{6}{|l|}{ Carcinoid } \\
\hline Bronchial & ND & $3 / 4(75)$ & ND & ND & $3 / 4(75)$ \\
\hline GI tract & ND & $14 / 16(88)$ & ND & ND & $14 / 16$ (88) \\
\hline \multicolumn{6}{|l|}{ Lung cancer } \\
\hline Adenocarcinoma & $1 / 20(5)$ & $0 / 20(0)$ & $1 / 20(5)$ & $10 / 20(50)$ & $2 / 20(10)$ \\
\hline Squamous/adenosquamous & $0 / 24(0)$ & $0 / 24(0)$ & $2 / 24(8)$ & $0 / 24(0)$ & $0 / 24(0)$ \\
\hline Small cell & $20 / 23(87)$ & $5 / 23(22)$ & $12 / 23(52)$ & $19 / 23(83)$ & $18 / 23(78)$ \\
\hline Large cell & $0 / 28(0)$ & $0 / 28(0)$ & $0 / 28(0)$ & $14 / 28(50)$ & $5 / 28(18)$ \\
\hline Large cell neuroendocrine & $9 / 12(82)$ & $6 / 12(50)$ & $6 / 12(50)$ & $12 / 12(100)$ & $6 / 12(50)$ \\
\hline $\begin{array}{l}\text { GI tract carcinoma with NE } \\
\text { component }^{a}\end{array}$ & $7 / 7$ (100) & $3 / 7$ (43) & $4 / 7(57)$ & $7 / 7$ (100) & $4 / 7(57)$ \\
\hline
\end{tabular}

All data are $n(\%)$. ND, not done.

a Seven cases include two of gastric adenocarcinoma with small cell carcinoma (SCC), one of adenocarcinoma of papilla vater with SCC, one of colon NE carcinoma, one of rectal adenocarcinoma with NE carcinoma, one of gall bladder adenocarcinoma with NE carcinoma, and one of esophageal squamous cell carcinoma with SCC. 
and (2) strongly positive staining in $\geq 10 \%$ of tumor cells.

\section{RESULTS}

\section{HDC Staining}

All pheochromocytomas (15 cases) and medullary carcinomas of the thyroid gland (4 cases) tested showed diffuse and strong cytoplasmic immunoreactivity with anti-HDC antibody (Figures 1A,B), as did normal adrenal chromaffin cells and thyroid gland C-cells (not shown).

The results of HDC staining of lung and gastrointestinal tumors are summarized in Table 1. An internal control was provided by neuroendocrine cells scattered in the bronchial epithelium, which were positive for HDC (not shown). Three of 4 bronchial carcinoid tumors were reactive with antiHDC antibody (1 focally and 2 strongly positive; Fig. 1C). Eighteen of 23 (78\%) of the small-cell lung carcinomas were strongly positive (Fig. 1D), and 6 of 12 large-cell neuroendocrine carcinomas were positive (Fig. 1E). With regard to nonneuroendocrine carcinoma, 2 of 20 adenocarcinomas and 2 of 28 large-cell carcinomas were focally reactive, and 3 of 28 large cell carcinomas were strongly positive (Fig. 1F). No HDC staining was observed in squamous cell carcinomas ( 0 of 21 ) and adenosquamous cell carcinomas ( 0 of 3 ). In total, 7 of 72 non-small and non-neuroendocrine tumors (9.7\%), and 27 of 39 neuroendocrine tumors $(69 \%)$, of the lung were HDC positive.

In the gastrointestinal tract, scattered HDCpositive cells were observed, possibly representing
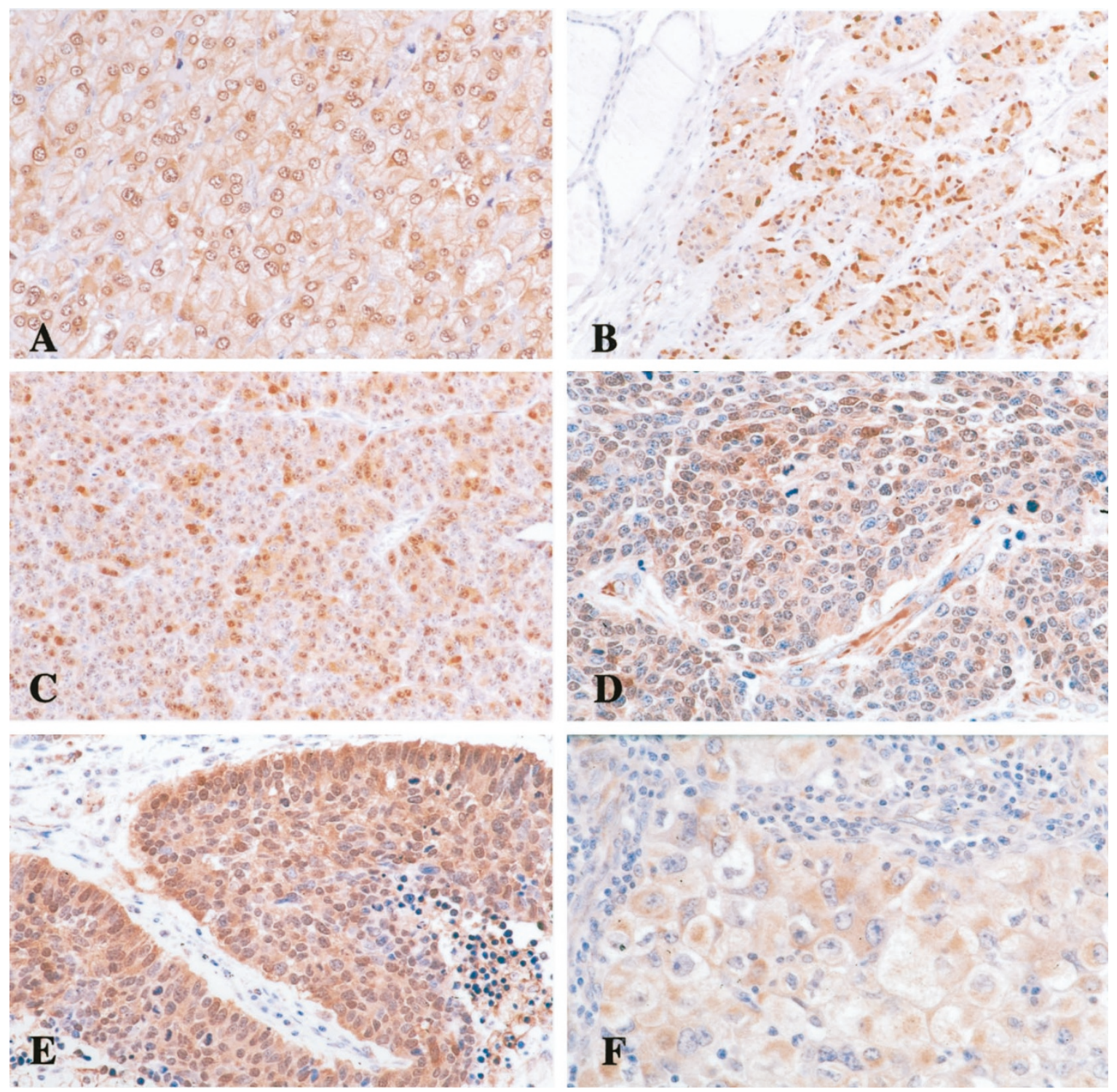

FIGURE 1. Immunohistochemical demonstration of HDC in pheochromocytoma (A), thyroid medullary carcinoma (B), and lung tumors (C-F). Diffuse cytoplasmic staining of HDC is evident. (C) bronchial carcinoid tumor, (D) small cell lung carcinoma, (E) large cell neuroendocrine carcinoma, and (F) large cell carcinoma. 
enterochromaffin-like and enterochromaffin cells (gastrointestinal-neuroendocrine cells; Fig. 2A). Among the gastrointestinal tumors, detectable HDC staining was observed in 14 of 16 carcinoid tumors $(88 \%, 2$ were focally positive, and the others were strongly positive), and 4 of 7 small cell carcinomas $(57 \%)$ were strongly positive only in the neuroendocrine components, except for 1 focally positive staining (Table 1 and Fig. 2C, 2D). The areas of adenocarcinoma and squamous cell carcinoma were negative for histidine decarboxylase.

\section{Neuroendocrine Markers in Resected Materials}

Results of staining for NSE, SYN, CGA, and CD56 are shown in Table 1. For pheochromocytomas, medullary carcinomas of the thyroid gland, and bronchial and gastrointestinal-carcinoid tumors, CGA immunoreactivity was $100 \%, 100 \%, 75 \%$, and $88 \%$, respectively. With regard to other lung and gastrointestinal carcinomas, an immunohistochemical panel was used to compare the sensitivity and specificity of HDC with those of other neuroendocrine markers. Staining for CD56 showed the highest (87\% positive) score, in small cell lung carcinomas, followed by NSE (83\%), SYN (26\%), and CGA (22\%). In large cell neuroendocrine carcinomas, the sensitivities were $82 \%$ (CD56), 100\% (NSE),
$33 \%$ (SYN), and 50\% (CGA), and all the large cell neuroendocrine carcinomas were positive for at least one of the neuroendocrine markers. On the other hand, large-cell carcinoma lacked positive staining for CD56, SYN, and CGA, and 50\% of cases were reactive for NSE. With regard to adenocarcinomas, adenosquamous cell carcinomas, and squamous cell carcinomas, one case of adenocarcinoma that was focally positive for HDC was also focally positive for CD56, SYN, and NSE. Another case each of adenosquamous cell carcinoma and squamous cell carcinoma were focally reactive for SYN. The percentage of positive staining for NSE was $41 \%$ in adenocarcinomas, adenosquamous cell carcinomas, and squamous cell carcinomas; among them, one adenocarcinoma was focally positive for both NSE and HDC.

In gastrointestinal small cell carcinomas, positive staining for the panel of antibodies was similar to that of large cell neuroendocrine carcinomas in the lung. CD56 and NSE were $100 \%$ positive (7 of 7 ), and CGA and SYN were reactive in $43 \%$ ( 3 of 7$)$ and $57 \%$ (4 of 7) cases, respectively.

Among the small cell lung carcinoma, one case was negative for all markers including HDC. On the other hand, three cases were positive for all markers. In Table 2, we summarized the frequency of the
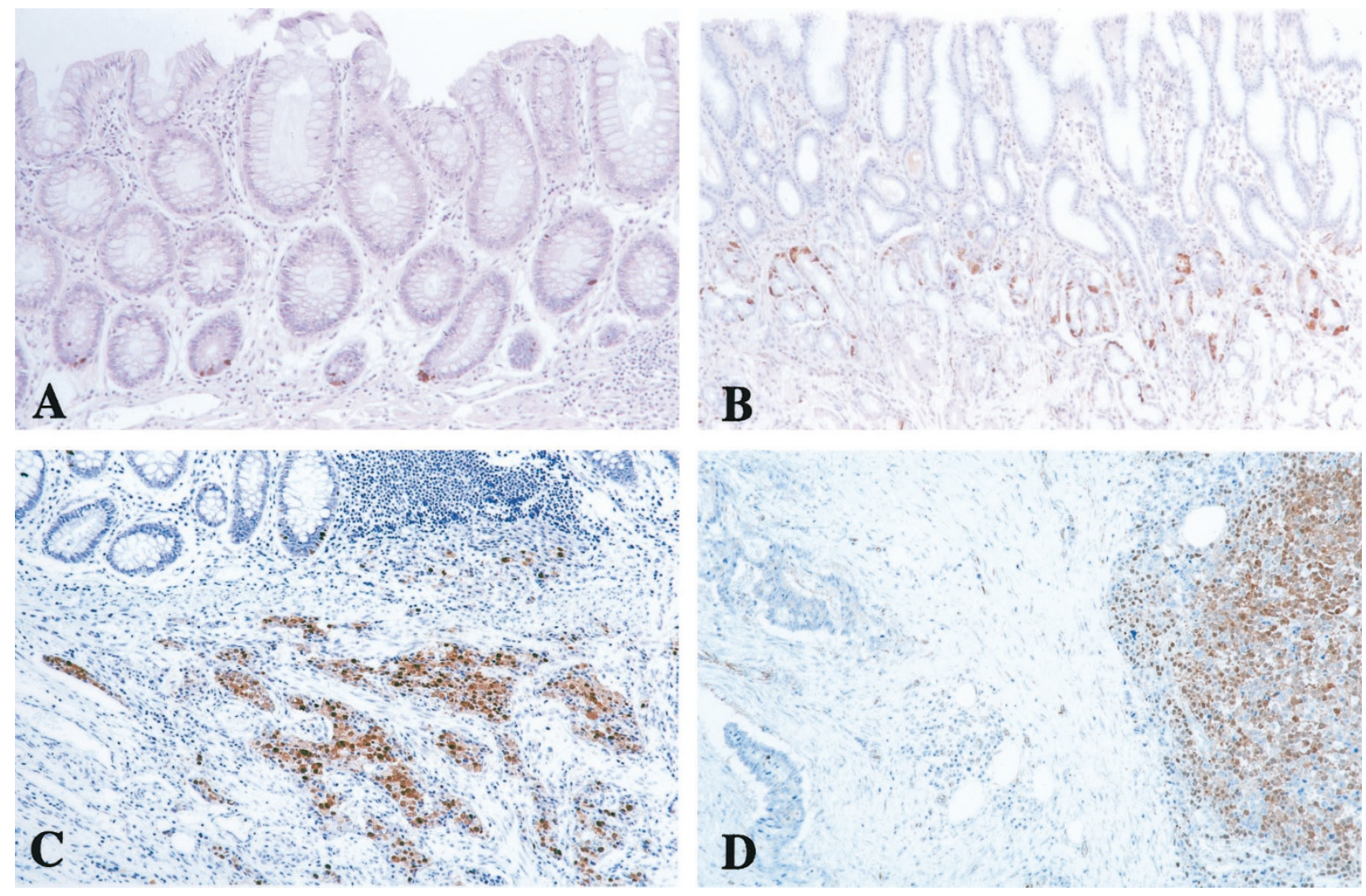

FIGURE 2. HDC staining in gastrointestinal neuroendocrine cells and tumors. Scattered HDC-positive cells are located in the gastric (A) and colonic (B) mucosa. (C) The cells of duodenal carcinoid tumor are strongly reactive with anti-HDC antibody. (D) Rectal cancer admixed with adenocarcinoma and small cell carcinoma. Note that HDC is positive only in the small cell carcinoma component. 


\begin{tabular}{|c|c|c|c|}
\hline No. of Positive Markers & & No. of Positive Cases & $\%$ of Positive Cases (\% HDC Positive) \\
\hline All negative & 1 & & \\
\hline 1 positive & 1 & $(1:$ NSE+) & $22 \%(6 \%)$ \\
\hline 2 positive & 3 & $\begin{array}{l}(1: \mathrm{NSE}+, \mathrm{HDC}+) \\
(1: \mathrm{CD} 56+, \mathrm{SYN}+) \\
(1: \mathrm{CD} 56+, \mathrm{NSE}+)\end{array}$ & Less than 3 markers \\
\hline 3 positive & 9 & $\begin{array}{l}\text { (6: } \mathrm{CD} 56+, \mathrm{NSE}+, \mathrm{HDC}+) \\
(2: \mathrm{CD} 56+, \mathrm{SYN}+, \mathrm{HDC}+) \\
(1: \mathrm{CD} 56+, \mathrm{NSE}+, \mathrm{SYN}+)\end{array}$ & $78 \%(94 \%)$ \\
\hline 4 positive & 6 & $\begin{array}{l}(4: \mathrm{CD} 56+, \mathrm{SYN}+, \mathrm{NSE}+, \mathrm{HDC}+) \\
(2: \mathrm{CD} 56+, \mathrm{CGA}+, \mathrm{NSE}+, \mathrm{HDC}+)\end{array}$ & More than 2 markers \\
\hline All positive & 3 & & \\
\hline Total positive (HDC positive) & & $23(18)$ & \\
\hline
\end{tabular}

reactivity of five neuroendocrine markers in the small cell lung carcinoma. Seventy-eight percent of cases $(18 / 23)$ of the small cell carcinoma were positive for three or more neuroendocrine markers, and $94 \%$ of HDC-positive cases (17/18) were also reactive to the other two or more markers.

\section{DISCUSSION}

In this study, we evaluated the possibility that HDC expression is a novel neuroendocrine differentiation marker. First of all, we investigated HDC expression in non-tumor neuroendocrine cells, and showed that adrenal chromaffin cells, thyroid gland C-cells, and gastrointestinal and bronchial neuroendocrine cells were strongly positive for HDC. Next, we expanded the application to neuroendocrine tumors, including pheochromocytomas, medullary carcinomas of the thyroid gland, and carcinoid tumor, which also showed intense and diffuse staining. This immunohistochemical demonstration of HDC in normal neuroendocrine cells and neuroendocrine tumors as a positive control indicated that HDC is an excellent marker for neuroendocrine differentiation.

Another amine precursor uptake and decarboxylation-related enzyme, L-dopa decarboxylase, is also highly expressed in pheochromocytomas (86\%), medullary carcinomas of the thyroid gland $(81 \%)$, and bronchial carcinoid tumors $(100 \%)$ and has been suggested to be a good marker for the neuroendocrine system (22). In general, however, pathologists do not experience difficulty in diagnosing these tumors. Therefore, a neuroendocrine marker must be able to distinguish between small cell lung carcinoma and nonneuroendocrine carcinoma and to demonstrate neuroendocrine differentiation in other neuroendocrine carcinomas. L-dopa decarboxylase has been found to be expressed even in undifferentiated small cell lung carcinoma ( $82 \%$ in Gould et al., 22). However, the L-dopa decarboxylase assay is performed with a biochemical method and requires fresh tumor tissue to extract the enzymatic activity.
On the other hand, only a few reports have demonstrated immunohistochemical localization of L-dopa decarboxylase in the neuroendocrine cells of the bronchial and gastrointestinal tract (28) and in small cell lung carcinomas (29). We do not know why the sensitivity of HDC in gastrointestinal small cell carcinomas was lower than that of small cell lung carcinomas. However, one possible explanation for the difference in detectability is related to the anatomical sites of the lesions. A similar situation has been reported for CD56 immunohistochemistry in carcinoid tumors (30). The incidence of CD56 immunoreactivity progressively decreased in foregut, midgut, and hindgut carcinoid tumors, whereas lung carcinoid tumors showed $100 \%$ staining for CD56 (30).

In contrast to the case of neuroendocrine tumors, HDC was rarely expressed in lung adenocarcinomas and squamous cell carcinomas $(5 \%, 2$ of 44; specificity, 0.95 ; see Table 3 ). The two positive cases of adenocarcinomas showed only focal staining with relatively less intensity. However, with regard to large cell carcinomas, a higher percentage of staining for HDC was observed (18\%, 5 of 28). The classification of large cell carcinomas remains a matter of debate, and it is suggested that large cell carcinoma may include four potential phenotypes $(26,27)$ : (1) large cell neuroendocrine carcinoma; (2) large cell carcinoma with neuroendocrine markers, but no neuroendocrine morphology; (3) large cell carcinoma with neuroendocrine morphology without neuroendocrine differentiation; and (4) classic large cell carcinoma with no neuroendocrine morphology or differentiation by special studies, includ-

TABLE 3. Sensitivity and Specificity of Neuroendocrine Markers for Small Cell Carcinomas

\begin{tabular}{lccccc}
\hline Parameter & HDC & CD56 & CGA & SYN & NSE \\
\hline Sensitivity & 0.78 & 0.87 & 0.22 & 0.52 & 0.83 \\
Specificity & 0.95 & 0.98 & 1.00 & 0.93 & 0.59 \\
\hline
\end{tabular}

The sensitivity and specificity were calculated as follows: sensitivity = true positive/(true positive + false negative); specificity $=$ true negative/ (true negative + false negative). 
ing immunohistochemistry or electron microscope (EM). In this study, we did not perform EM, and we had no cases with the appearance of Category 2 or 3 if we use the immunohistochemical results to identify neuroendocrine differentiation. If we consider that HDC is a useful marker to of neuroendocrine differentiation, the five large cell carcinoma cases may be categorized as large cell carcinoma with neuroendocrine differentiation showing no neuroendocrine morphology. Interestingly, four of the five HDC-positive large cell carcinomas were also reactive for NSE.

Even though the detectability of HDC was not so high in large cell neuroendocrine carcinoma and gastrointestinal-small cell carcinoma, the very low expression in adenocarcinoma and squamous cell carcinoma and the higher sensitivity for small cell lung carcinoma suggest the utility of HDC as a new neuroendocrine marker to separate small cell lung carcinoma from non-small cell lung carcinoma and non-neuroendocrine carcinoma. In accordance with other published results $(7,31,32)$, the specificities of CD56, CGA, and SYN were very high, and that of HDC was also high enough to be useful as a neuroendocrine marker (Table 3). On the other hand, the specificity of NSE was lower than that of other markers. This restricts the usefulness of NSE, even though its sensitivity was as high as that of the other markers. Currently, anti-NSE antibody is used as a tool for primary screening $(4,33)$. The reported sensitivity of CGA and SYN for small cell lung carcinoma varies from 0.0 to $1.0(4,7,8,31,32,34)$. Because these markers are components of neurosecretory granules (1) and synaptic vesicles (35), respectively, their detectability is directly linked to the numbers of subcellular organelles (2). In our study, the immunoreactivity of CGA and SYN for small cell lung carcinoma was 0.22 and 0.52 , respectively (Table 3 ). On the other hand, CD56 is an adhesion molecule expressed on cell membranes $(7,36)$, and HDC is an enzyme localized in the endoplasmic reticulum (9). These two markers showed a relatively higher sensitivity compared with CGA and SYN. The difference in subcellular localization of marker proteins may influence their detectability.

In conclusion, we demonstrated that HDC is a useful diagnostic tool for distinction between small cell lung carcinoma and non-neuroendocrine carcinoma in combination with other conventional markers.

\section{REFERENCES}

1. Wilson RS, Lloyd RV. Detection of chromogranin in neuroendocrine cells with a monoclonal antibody. Am J Pathol 1984; 115:458-68.

2. Wick MR. Immunohistology of neuroendocrine and neuroectodermal tumors. Semin Diagn Pathol 2000;17:194-203.
3. Walts AE, Said JW, Shintaku P. Chromogranin as a marker of neuroendocrine cells in cytologic material-an immunocytochemical study. Am J Clin Pathol 1984;84:273-7.

4. Said JW, Vimadalal S, Nash G, Shintaku P, Heusser RC, Sassoon AF, et al. Immunoreactive neuron-specific enolase, bombesin, and chromogranin as markers for neuroendocrine lung tumors. Hum Pathol 1985;16:236-40.

5. Dardick I, Christensen H, Stratis M. Immunoelectron microscopy for chromogranin A in small cell neuroendocrine carcinoma of lung. Ultrastruct Pathol 1996;20:361-8.

6. Haimoto H, Takahashi Y, Koshikawa T, Nagura H, Kato K. Immunohistochemical localization of gamma-enolase in normal human tissue other than nervous and neuroendocrine tissues. Lab Invest 1985;52:257-63.

7. Kaufmann O, Georgi T, Dietel M. Utility of 123C3 monoclonal antibody against CD56 (NCAM) for the diagnosis of small cell carcinomas on paraffin sections. Hum Pathol 1997;28: 1373-8.

8. Liu Y, Sturgis CD, Grzybicki DM, Jasnosz KM, Olson PR, Tomg M, et al. Microtubule-associated protein-2: a new sensitive and specific marker for pulmonary carcinoid tumor and small cell carcinoma. Mod Pathol 2001;14:880-5.

9. Tanaka S, Nemoto K, Yamamura E, Ichikawa A. Intracellular localization of the 74- and 53-kDa forms of L-histidine decarboxylase in a rat basophil/mast cell line, RBL-2H3. J Biol Chem 1998;273:8177-82.

10. Kubota H, Taguchi Y, Tohyama M, Matsuura N, Shiosaka S, Ishihara $\mathrm{T}$, et al. Electron microscopic identification of histidine decarboxylase-containing endocrine cells of the rat gastric mucosa. An immunohistochemical analysis. Gastroenterology 1984;87:496-502.

11. Taguchi Y, Tsuyama K, Watanabe T, Wada H, Kitamura Y. Increase in histidine decarboxylase activity in skin of genetically mast-cell-deficient W/W mice after application of phorbol 12-myristate 13-acetate: evidence for the presence of histamine-producing cells without basophilic granules. Proc Natl Acad Sci U S A 1982;79:6837-41.

12. Higuchi S, Tanimoto A, Arima N, Xu H, Murata Y, Hamada T, et al. Effects of histamine and interleukin-4 synthesized in arterial intima on phagocytosis by monocytes/macrophages in relation to atherosclerosis. FEBS Lett 2001;505:217-22.

13. Falus A, Meretey K. Histamine: an early messenger in inflammatory and immune reactions. Immunol Today 1992; 13:154-6.

14. Novak I, Falus A. Molecular biology and role of histamine in physiological and pathological reactions. A review. Acta Biol Hung 1997;48:385-94.

15. Champion HC, Bivalacqua TJ, Lambert DG, Abassi RA, Kadowitz PJ. Analysis of vasoconstrictor responses to histamine in the hind limb vascular bed of the rabbit. Am J Physiol 1999;277:R1179-87.

16. Melnyk DL. Update on carcinoid syndrome. AANA J 1997; 65:265-70.

17. Kolby L, Wangberg B, Ahlman H, Jansson S, ForssellAronsson E, Erickson JD, et al. Gastric carcinoid with histamine production, histamine transporter and expression of somatostatin receptors. Digestion 1998;59:160-6.

18. Adams WJ, Lawson JA, Morris DL. Cimetidine inhibits in vivo growth of human colon cancer and reverses histamine stimulated in vitro and in vivo growth. Gut 1994;25:1632-6.

19. Takahashi K, Tanaka S, Ichikawa A. Effect of cimetidine on intratumoral cytokine expression in an experimental tumor. Biochem Biophys Res Commun 2001;281:1113-6.

20. Hegysei H, Somlai B, Varga VL, Toth G, Kovacs P, Molnar EL, et al. Suppression of melanoma cell proliferation by histidine decarboxylase specific antisense oligonucleotides. J Invest Dermatol 2001;117:151-3. 
21. Pearse AGE. The amine precursor uptake and decarboxylation cell concept and its implications in pathology. Pathol Annu 1974;9:27-41.

22. Gould VE, Memoli V, Chejfec G, Johannessen JV. The amine precursor uptake and decarboxylation cell system and its neoplasm: observation on the significance and limitations of the concept. Surg Clin North Am 1979;59: 93-108.

23. Jensen SM, Gazdar AF, Cuttitta F, Russell EK, Linnoila RI. A comparison of synaptophysin, chromogranin, and L-dopa decarboxylase as markers for neuroendocrine differentiation in lung cancer cell lines. Cancer Res 1990;50:6068-74.

24. Gazdar AF, Helman LJ, Israel MA, Russell EK, Linnoila RI, Mulshine JL, et al. Expression of neuroendocrine cell markers L-dopa decarboxylase, chromogranin A, and dense core granules in human tumors of endocrine and neuroendocrine origin. Cancer Res 1988;48:4078-82.

25. Graff L, Frungieri M, Zanner R, Pohlinger A, Prinz C, Gratzl M. Expression of histidine decarboxylase and synthesis of histamine by human small cell lung carcinoma. Am J Pathol 2002;160:1561-5.

26. Travis WD, Colby TV, Corrin B, Shimosato Y, Brambilla E. World Health Organization Histological typing of lung and pleural tumors. 3rd ed. New York: Springer; 1999.

27. Travis WD, Linnoila RI, Tsokos MG, Hitchcock CL, Cutler GB, Nieman L, et al. Neuroendocrine tumors of the lung with proposed criteria for large-cell neuroendocrine carcinoma. Am J Surg Pathol 1991;15:529-33.

28. Lauweryns JM, Van Ranst L. Immunohistochemical localization of aromatic L-amino acid decarboxylase in human, rat, and mouse bronchopulmonary and gastrointestinal endocrine cells. J Histochem Cytochem 1988;36:1181-6.

29. Nakajima T, Shimosato Y, Morinaga S, Terasaki T, Tsumuraya $\mathrm{M}$, Yamaguchi $\mathrm{K}$, et al. Immunohistochemical study of small cell carcinoma with special reference to the neuroendocrine markers aromatic L-amino acid decarboxylase and gastrin-releasing peptide. Jpn J Clin Oncol 1986;16:223-33.

30. Al-Khafaji B, Noffsinger AE, Miller MA, DeVoe G, Stemmermann GN, Fenoglio-Preiser C. Immunohistologic analysis of gastrointestinal and pulmonary carcinoid tumors. Hum Pathol 1998;29:992-9.

31. Loy TS, Darkow GVD, Quesenberry JT. Immunostaining in the diagnosis of pulmonary neuroendocrine carcinomas: an immunohistochemical study with ultrastructural correlations. Am J Surg Pathol 1995;19:173-82.

32. Lyda MH, Weiss LM. Immunoreactivity for epithelial and neuroendocrine antibodies are useful in the differential diagnosis of lung carcinomas. Hum Pathol 2000;31:980-7.

33. Delellis RA. Endocrine tumors. New York: Raven Press; 1988.

34. Linnoila RI, Mulshine JL, Steinberg SM, Funa K, Matthews MJ, Cotelingam JD, et al. Neuroendocrine differentiation in endocrine and neuroendocrine lung carcinomas. Am J Clin Pathol 1988;90:641-52.

35. Gould VE, Lee I, Wiedenmann B, Moll R, Chejfec G, Franke WW. Synaptophysin. A novel marker for neurons, certain neuroendocrine cells, and their neoplasms. Hum Pathol 1986;17:979-83.

36. Rutishauser U, Acheson A, Hall AK, Mann DM, Sunshine J. The neural cell adhesion molecule (NCAM) as a regulator of cell-cell interactions. Science 1988;240:53-7. 